\title{
Первая неделя технологий информационного общества в Санкт-Петербурге
}

\author{
М.В. Кудрявцева ${ }^{1,2}$, Д.Е. Прокудин ${ }^{2,1}$, А.А. Смолин ${ }^{2,1}$, А.В. Чугунов ${ }^{1}$ \\ ${ }^{1}$ Университет ИТМО, Россия \\ ${ }^{2}$ Санкт-Петербургский государственный университет, Россия \\ mvkudriavtceva@corp. ifmo.ru, hogben. young@gmail.com, \\ artikus@inbox.ru, egov-center@yandex.ru
}

\begin{abstract}
Аннотация. С 21 по 24 июня 2016 года в Санкт-Петербурге прошла Неделя технологий информационного общества, которая включила в себя ряд научных мероприятий (конференций, круглых столов и симпозиумов). Базовым мероприятием Недели является традиционно проводимая начиная с 1998 года объединённая научная конференция «Интернет и современное общество» (IMS). Данный обзор раскрывает основные темы и проблемы, которые были обсуждены на научных мероприятиях Недели технологий информационного общества, которая прошла в 2016 году впервые.
\end{abstract}

Ключевые слова: технологии информационного общества, конференция, круглый стол, симпозиум, Интернет, современное общество.

Представители научного сообщества, чьи профессиональные интересы лежат в плоскости исследования различных аспектов влияния технологий на общественное развитие, на протяжении двух десятилетий объединены ежегодно проводимой конференцией «Интернет и современное общество» (Internet and Modern Society - IMS). В 2016 году при подготовке к проведению ХIX Конференции организационный комитет столкнулся с проявлением большого интереса к запланированному международному симпозиуму как со стороны отечественных, так и зарубежных исследователей различных аспектов развития современного информационного общества. Поэтому организаторами конференции было принято решение трансформировать этот симпозиум в полноценную международную конференцию «Цифровые трансформации и глобальное общество» (Digital Transformations \& Global Society - DTGS). В связи с запланированным проведением нескольких мероприятий на протяжении нескольких дней организаторы конференции решили объединить их Неделей технологий информационного общества в Санкт-Петербурге. В рамках Недели были проведены следующие научные мероприятия:

- 21 июня - круглый стол «Эпоха информатизации или кто управляет миром?» (гостиница СОКОС (Solo Sokos Hotel Palace Bridge), В.О., Биржевой пер., д.2-4, зал "Фокстрот"). Рабочий язык - русский. 
- 21 июня - симпозиум молодых учёных (гостиница СОКОС (Solo Sokos Hotel Palace Bridge), B.О., Биржевой пер., д.2-4, зал "Фокстрот"). Рабочий язык - русский.

- 22 июня - круглый стол «Экология музейной информационной системы» (Университет ИТМО, Биржевая линия, 14). Рабочий язык - русский.

- 22-23 июня-мероприятия конференции «Интернет и современное общество» (БАН, Биржевая линия, 1). Рабочий язык - русский.

- 23-24 июня - международная конференция «Digital Transformation \& Global Society» (Университет ИТМО, Биржевая линия, 4). Рабочий язык - английский.

- 23-24 июня - международная конференция EVA 2016 Saint Petersburg (Electronic Imaging \& the Visual Arts) (Государственный Русский Музей, Инженерная ул, 8). Рабочий язык английский.

Открывал Неделю технологий информационного общества круглый стол "Эпоха информатизации или кто управляет миром?". Его задачей явилось привлечение внимания широкой общественности к злободневным темам развития информационного общества. В работе круглого стола приняли участие ученые, известные политики, общественные деятели и представители IT бизнеса, а также участники молодежного симпозиума, от которых будет зависеть, каким станет информационное пространство в ближайшем будущем. Основные темы дискуссии: «Открытое общество - как соблюсти баланс интересов?» и «Какова роль информационных технологий и ответственность тех, кто их создает?»

Вёл мероприятие Зинчук Юрий Юрьевич, тележурналист, Заместитель Генерального директора телеканала «Санкт-Петербург» по общественно-политическому вещанию. Ведущий программ «Пульс города», «Партбюро».

Ключевыми спикерами выступили:

- Шишлов А.В., уполномоченный по правам человека в Санкт-Петербурге;

- Засурский Иван Иванович, канд. филол. наук, заведующий кафедрой новых медиа Факультета журналистики МГУ, президент Ассоциации интернет-издателей;

- Казин Ф.А., канд. ист. наук, декан факультета технологического менеджмента и инноваций Университета ИТМО;

- Чугунов А.В., канд. полит. наук, заведующий кафедрой управления государственными информационными системами Университета ИТМО, Директор Центра технологий электронного правительства.

В работе Круглого стола приняло участие 53 человека в качестве слушателей и участников дискуссии. Среди них присутствовали студенты и молодые ученые из Санкт-Петербурга и других городов.

После окончания Круглого стола был проведён симпозиум молодых учёных «Киберпространство: перспективные социально-экономические и гуманитарные исследования», который объединил студентов и молодых учёных и исследователей из Санкт-Петербурга и других городов.

Руководитель Симпозиума - заведующий кафедрой маркетинга и коммуникаций, д.э.н., проф. проф. Будрин А.Г.; организаторы - заместитель заведующего кафедрой маркетинга и коммуникаций, к.э.н., доц. Соловьева Д.В. и ст. преп. кафедры МиК Емцова М.Г.; секретарь Зенченкова К.С., инженер, магистрант кафедры УГИС Университета ИТМО.

Симпозиум был посвящён обсуждению тематики по следующим направлениям:

- Электронное правительство, электронное управление;

- Электронный бизнес, электронная коммерция, онлайн услуги;

- Информационная безопасность и «Чистый Интернет»;

- Мониторинг использования ИКТ и развития информационных ресурсов Интернета;

- Организационно-правовая специфика развития информационных ресурсов Интернета;

- Социальные сети и виртуальные среды для научных исследований;

International Culture \& Technology Studies, Vol. 2, No. 1 
- Дистанционное и сетевое обучение;

- Новые медиа и информационное общество;

- Социальные сети и виртуальные среды для научных исследований;

- Электронное участие, прозрачность и антикоррупция.

Организаторы отмечают разносторонний характер выступлений в контексте заявленной тематики Симпозиума, глубину проработки тем выступлений и высокую степень мотивированности и готовности участников к самостоятельным научным исследованиям.

В работе Симпозиума приняли участи 36 человек, студентов и аспирантов Университета ИТМО и других вузов Санкт-Петербурга и России. Выступили с докладами 13 участников. Организаторы и участники Симпозиума отметили следующие выступления:

- Системы дискавери: роль в навигации по электронным ресурсам (Снеткова Анна, аспирант, СПбГУКИ);

- Социальные сети как инструмент выражения гражданской позиции (на примере Украины) (Чередник Анастасия, аспирант, МПГУ);

- Открытость муниципальной власти Санкт-Петербурга в сети Интернет (Чичканова Дарья, магистрант, СПбГУ);

- Коммуникационный канал Интернет как средство диффузии инноваций и трансфера технологий (Бакштай Даниил, магистрант, Университет ИТМО);

- Влияние технологии на качество маркетингового исследования методом onlineанкетирования (Финикова Ольга, магистрант, Университет ИТМО);

- Современные коммуникационные технологии в контексте биполярности рекламного сообщения (Алексеев Роман, аспирант, СПбГУ);

- Влияние информационных технологий на бренд вуза (Долгодворова Карина, магистрант, СПбГУ);

- Анализ конъюнктуры интернет-рынка на примере динамики развития интернет-магазинов (Мороз Мария, бакалавр, СПбГПУ).

22 июня состоялось открытие XIX Международной объединенной научной конференции «Интернет и современное общество» (Internet and Modern Society - IMS). Открыла работу конференции Колпакова Н.В., канд. пед. наук, заместитель директора Библиотеки Российской академии наук. С приветственным словом выступили Борисов Н.В., докт. физ.-мат. наук, директор Центра дизайна и мультимедиа Университета ИТМО, зав. кафедрой информационных систем в искусстве и гуманитарных науках СПбГУ и Леонов В.П., докт. пед. наук, научный руководитель Библиотеки Российской академии наук. Программу конференции представил Чугунов А.В., канд. политич. наук, заведующий кафедрой УГИС ФТМИ Университета ИТМО, ученый секретарь объединенной конференции IMS-2016.

Затем состоялась пленарная сессия в форме междисциплинарной дискуссии на тему «Парадигма «открытой науки» как устойчивая тенденция развития информационного общества». В ней приняли участие следующие основные докладчики:

- Горбунов-Посадов М.М., доктор физ.-мат. наук, заведующий отделом Института прикладной математики им.М.В.Келдыша РАН;

- Радченко И.А., канд. техн. наук, доцент кафедры информатики и прикладной математики Университета ИТМО;

- Засурский И.И., канд. филол. наук, заведующий кафедрой новых медиа и теории коммуникации факультета журналистики МГУ им. М. В. Ломоносова, президент Ассоциации интернет-издателей.

- В качестве дискурсанта - Чугунов А.В., канд. политич. наук, заведующий кафедрой УГИС ФТМИ Университета ИТМО.

В выступлениях докладчиков были затронуты технологические, правовые, культурные и социальные аспекты решения проблем, связанных с реализацией парадигмы «открытой науки» в России. В ходе обсуждения этого многоаспектного явления была проанализирована и получила 
оценку инициатива «Общественное достояние», которая рассматривает результаты научных исследований с точки зрения открытости, доступности и бесплатности для всего общества.

22 и 23 июня в рамках Конференции были проведены следующие секции и круглые столы:

- Секция «Компьютерная лингвистика и вычислительные онтологии», 22 июня.

- Круглый стол «Электронное правительство: управление государственными информационными системами», 22 июня.

- Круглый стол «Возрастные особенности в практиках реализации технологий информационного общества», 22 июня.

- Секция «Информационные системыдля науки и образования», 23 июня.

- Секция «Электронное обучение и дистанционные образовательные технологии», 23 июня.

- Секция «Культурология киберпространства», 23 июня.

В завершении работы конференции были подведены итоги работы секций и круглых столов, а также состоялись заключительная дискуссия, обсуждения и краткие выступления участников конференции. С заключительным словом от организаторов Конференции выступили:

- Колпакова Н.В., канд. пед. наук, заместитель директора Библиотеки Российской академии наук, член Программного комитета;

- Прокудин Д.Е., докт. филос. наук, доцент кафедры логики Санкт-Петербургского государственного университета, заместитель председателя Оргкомитета.

Для участия в конференции с докладами и последующей публикацией статей или тезисов было подано 65 заявок, в том числе 2 от иностранных участников. В процессе рецензирования экспертами из соответствующих областей было отобрано 33 доклада. Всего с докладами выступило 37 участников. Также в дискуссиях конференции и работе секций приняли участие 32 сотрудника Библиотеки РАН. Всего в работе конференции приняло участие 160 участников.

К основным результатам конференции «Интернет и современное общество» в 2016 году можно отнести то, что были предложены и обсуждены различные подходы, тем или иным образом связанные с реализацией проблемы сохранения культурного наследия - как материального, так и не материального. В том числе были затронуты вопросы сохранения, аккумуляции и обеспечения доступа к результатам научных исследований, которые, в том числе, представляют собой научное культурное наследие. Предложенные в докладах результаты исследований и разработок могут быть использованы при реализации парадигмы «открытой науки» и интеграции отечественной науки в мировое научное информационное пространство.

22 июня был проведён круглый стол «Экология музейной информационной системы» по вопросам формирования музейных информационных систем. Основная цель круглого стола объединить музейных специалистов по цифровому контенту, разработчиков и поставщиков софта и оборудования и обсудить роль информационного управления в проектировании, создании и поддержке музейных информационных систем.

В круглом столе приняли участие музейные специалисты, инженеры, системные администраторы и представители коммерческих компаний и разработчиков, занимающихся широким спектром разработок программного обеспечения и интернет решений, а также поставкой серверного и пользовательского оборудования для музеев и других учреждений, обеспечивающих доступ к цифровому культурному наследию.

В работе круглого стола приняли участие 34 человека.

Круглый стол был посвящён памяти инициатора мероприятия - эксперта в области музейных информационных проектов Татьяны Богомазовой, заведовавшей отделом информационных технологий Музея антропологии и этнографии имени Петра Великого (Кунсткамера) Российской академии наук.

C 23 по 24 июня 2016 года была проведена Международная научная конференция EVA 2016 SAINT PETERSBURG (Electronic Imaging \& the Visual Arts). Конференция была организована Университетом ИТМО совместно с Государственным русским музеем и Centro per la comunicazione e l'integrazione dei media (micc), Università degli Studi di Firenze. Целью конференции стало предоставление дискуссионной площадки специалистам и ученым гуманитарных и

International Culture \& Technology Studies, Vol. 2, No. 1 
технических специальностей для обсуждений, обмена опытом, идеями и планами по широкому спектру вопросов применения информационных технологий в культуре и искусстве. Участники получили актуальную информацию о тенденциях развития информационно-коммуникационных технологий (ИКТ) и их приложения в области сохранения культурного наследия, а также узнали о новых результатах проектов в сфере культуры, искусства, археологии и истории, полученных с использованием ИКТ.

В работе конференции приняли участие специалисты, ведущие исследования в области технологий и визуальных искусств, представители организаций культуры и искусства, органов власти, туристического бизнеса, СМИ, а также специалисты из индустрии информационнокоммуникационных технологий, в том числе - разработчики мультимедиа-систем из сектора малого бизнеса.

Участники конференции представили доклады на английском языке в рамках следующих направлений:

- $2 \mathrm{D}-3 \mathrm{D}$ цифровая обработка изображений.

- Цифровые приложения для музеев, библиотек, галерей, археологических и исторических памятников, образовательных учреждений. Музейные экскурсии и исторические туры.

- Интегрированные цифровые архивы для сохранения культурного наследия и современного искусства.

- Музейный менеджмент с использованием информационно-коммуникационных технологий: доступ к архивной информации, документации, экскурсиям и другим услугам.

- Виртуальная реальность.

- Технологии мультимедиа $360^{\circ}$.

- Виртуальные музеи и галереи.

- Человеко-компьютерное взаимодействие в приложениях к обеспечению доступа к культурному наследию.

- Развитие дизайна и его приложения.

- Развитие 3D-технологий и приложения в области культурного наследия.

- Защита авторских прав (маркировка водяными знаками, борьба с пиратством, электронная коммерция).

- Культура и электронное правительство.

- Разработка и реализация программ e-learning.

- Креативные индустрии.

- Экосистема распределения цифрового контента.

- Цифровые театры.

- Приложения для культурного туризма и путешествий.

- Искусство и медицина.

На конференцию было подано 73 заявки. Всего в работе конференции приняло участие 75 человек, из них 27 иностранных исследователей.

Конференция проводилась совместно с Государственным русским музеем в Центре Мультимедиа Русского музея. В рамках конференции состоялся телемост с двумя университетами Лондона: University - London, Ravensbourne (RAVE) и London South Bank University. С британской стороны в телемосте участвовало по 10 человек от каждого университета.

Работу международной конференции «Цифровые трансформации и глобальное общество» (Digital Transformations \& Global Society - DTGS) предваряла постерная сессия, которая состоялась 22 июня в здании Университета ИТМО. С постерными докладами в ней принял участие 31 учёный. Общее число участников составило 56 человек. В непринуждённом общении авторы постерных докладов отвечали на вопросы участников и принимали участие в дискуссиях.

Основная часть Конференции проходила 23 и 24 июня. Главная цель конференции создание представительной площадки для академического и профессионального обсуждения современных тенденций развития информационного общества. Темой научной дискуссии 
конференции стали вопросы информационных, социальных, экономических, политических и культурных изменений, связанных с развитием цифровых технологий.

Научная программа конференции DTGS была выстроена по пяти ключевым направлениям:

- eSociety: рассмотрение вопросов взаимодействия современных технологий и общественнополитических институтов, представление результатов исследований социальных сетей и сообществ, краудсорсинга и электронного участия граждан в делах государства.

- eCity: обсуждение перспектив, проблем и лучших практик в области муниципальной политики, развития городской инфраструктуры и построения «умных городов». Важным аспектом дискуссии станет синтез информационных технологий и урбанистики для повышения уровня жизни граждан, а также развития городских социальных и деловых коммуникаций.

- eHealth: различные вопросы, связанные с внедрением информационных технологий в сферу здравоохранения: от использования ИКТ для диагностики и лечения до управления отраслью с помощью современных методов сбора и обработки данных.

- eScience: синтез информатики и научного знания позволяет ставить новые задачи и решать их новыми методами, с использованием сложных вычислений и больших данных, что повышает точность анализа и прогноза.

- eKnowledge: ИКТ открывают новые возможности для глобального доступа современному инструментарию извлечения знаний, а университеты, библиотеки и академические сообщества адаптируются к новой коммуникационной среде.

На конференцию «Цифровые трансформации и глобальное общество» было подано 157 заявок на участие с докладами. Все заявленные статьи прошли процедуру двойного слепого рецензирования членами международного программного комитета конференции. По итогам рецензирования был отобран 61 доклад, доля принятых докладов составила 39\%. Все принятые работы были опубликованы сборнике серии "Communications in Computer and Information Science" издательства "Springer", индексируемой Scopus и Web of Science (http://link.springer.com/book/10.1007\%2F978-3-319-49700-6).

На конференции также были представлены два пленарных доклада - Питера Слоота, профессора Университета Амстердама, на тему «Наука о поведении сложных систем и Интернет вещей», а также Латифа Ладида, сотрудника Университета Люксембурга и президента Форума IPv6, на тему «Новый Интернет IPv6 как мотор развития инновационного и живого «электронного общества».

Для информационной и организационной поддержки подготовки и проведения научных мероприятий, проводимых в рамках Недели технологий информационного общества, были созданы и использовались следующие информационные ресурсы:

1) Сайт Международной объединенной научной конференции «Интернет и современное общество» (Internet and Modern Society - IMS) и симпозиума молодых учёных «Киберпространство: перспективные социально-экономические и гуманитарные исследования»: http://ims.ifmo.ru.

2) Сайт Международной научной конференции EVA SAINT PETERSBURG (Electronic Imaging \& the Visual Arts) и круглого стола «Экология музейной информационной системы»: http://evaspb.ifmo.ru.

3) Сайт международной конференции «Цифровые трансформации и глобальное общество» (Digital Transformations \& Global Society - DTGS): http://dtgs.ifmo.ru.

Кроме этого приём заявок на участие в международной конференции «Цифровые трансформации и глобальное общество» был организован через информационную систему поддержки конференций EasyChair (https://easychair.org/conferences/?conf $=$ dtgs2016). В этой же системе производилось рецензирование поданных текстов.

Мероприятия Недели технологий информационного общества освещены в репортажах на портале Университета ИТМО:

International Culture \& Technology Studies, Vol. 2, No. 1 
управления

1. «Интернет и современное общество»: технологизация науки, образования, культуры и (http://www.ifmo.ru/ru/viewnews/5762/internet i sovremennoe obschestvo tehnologizaciya nauki, obr azovaniya, kultury i upravleniya.htm).

2. EVA-2016: Виртуальный музей, 3D-театр, домашние экскурсии и личный Пол Маккартни (http://www.ifmo.ru/ru/viewnews/5765/EVA-2016_virtualnyy_muzey,_3Dteatr,_domashnie_ekskursii_i_lichnyy_pol_makkartni.htm).

3. Человек и Общество: в Петербурге стартовала конференция о влиянии технологий на жизнь

(http://www.ifmo.ru/ru/viewnews/5764/ichelovek_i iobschestvo_v peterburge startovala konferenciya o_vliyanii tehnologiy na zhizn lyudey.htm).

4. На выставку с мобильником: высокие музейные технологии обсудили на круглом столе B Университете ИТМО (http://www.ifmo.ru/ru/viewnews/5760/na vystavku s mobilnikom vysokie muzeynye tehnologii obs udili_na_kruglom_stole_v_universitete_itmo.htm).

Тексты статей докладов, принятых к участию в международной конференции «Цифровые трансформации и глобальное общество» (Digital Transformations \& Global Society - DTGS), опубликованы в сборнике научных статей издательства Springer.

По итогам работы конференций были изданы следующие сборники трудов:

1. Информационное общество: образование, наука, культура и технологии будущего: сборник научных статей. Труды XIX Международной объединенной научной конференции «Интернет и современное общество» (IMS-2016), Санкт-Петербург, 22 - 24 июня 2016 г. - СПб: Университет ИТМО, 2016. - 200 с. ISBN 978-5-7577-0533-0.

2. Государство и граждане в электронной среде: сборник научных статей. Труды XIX Международной объединенной научной конференции «Интернет и современное общество» (IMS2016), Санкт-Петербург, 22 - 24 июня 2016 г. -СПб: Университет ИТМО, 2016. - 108 с. ISBN 978-5-7577-0534-7.

3. Компьютерная лингвистика и вычислительные онтологии: сборник научных статей. Труды XIX Международной объединенной научной конференции «Интернет и современное общество» (IMS-2016), Санкт-Петербург, 22 - 24 июня 2016 г. - СПб: Университет ИТМО, 2016. - 80 c. ISBN 978-5-7577-0532-3.

4. Интернет и современное общество: сборник тезисов докладов. Труды XIX Международной объединенной научной конференции «Интернет и современное общество» (IMS2016), Санкт-Петербург, 22-24 июня 2016 г. - СПб: Университет ИТМО, 2016. - 80 с.

5. EVA 2016 SAINT PETERSBURG. Electronic Imaging \& the Visual Arts. INTERNATIONAL CONFERENCE, St. PETERSBURG, JUNE 23rd-24th, 2016. Conference Proceedings. - SPb ITMO University, 2016. - 144 p. ISBN 978-5-7577-0535-4.

6. Digital Transformation and Global Society. First International Conference, DTGS 2016, St. Petersburg, Russia, June 22-24, 2016, Revised Selected Papers. Communications in Computer and Information Science. Volume 674. 2016. DOI: 10.1007/978-3-319-49700-6.

Сборник тезисов докладов, представленных на XIX Международную объединенную научную конференцию «Интернет и современное общество» (Internet and Modern Society - IMS) выпущен в электронном виде.

В соответствии с положением об обязательном экземпляре (Федеральный закон от 29 декабря 1994 г. N 77-ФЗ "Об обязательном экземпляре документов") по 16 экземпляров каждого сборника переданы в издательство Университета ИТМО для отправки в Российскую книжную палату.

Полные тексты статей в электронном виде размещены в открытом репозитории Университета ИТМО (http://openbooks.ifmo.ru): 
- Информационное общество: образование, наука, культура и технологии будущего (http://openbooks.ifmo.ru/ru/collections_paper/41/informacionnoe_obschestvo:_obrazovanie_nau ka_kultura_i_tehnologii_buduschego.htm);

- Государство и граждане в электронной среде (http://openbooks.ifmo.ru/ru/collections_paper/42/gosudarstvo_i_grazhdane_v_elektronnoy_sred e.htm);

- Компьютерная лингвистика и вычислительные онтологии (http://openbooks.ifmo.ru/ru/collections_paper/43/kompyuternaya_lingvistika_i_vychislitelnye_o ntologii.htm);

- EVA 2016 SAINT PETERSBURG. Electronic Imaging \& the Visual Arts. INTERNATIONAL CONFERENCE, St. PETERSBURG, JUNE 23rd-24th, 2016. Conference Proceedings (http://openbooks.ifmo.ru/ru/collections_paper/45/eva_2016_sanktpeterburg_elektronnoe_predstavlenie_i_vizualnye_iskusstva_trudy_konferencii.htm);

- Сборник тезисов докладов трудов XIX объединенной конференции «Интернет и современное общество» (http://openbooks.ifmo.ru/ru/collections_paper/44/sbornik_tezisov_dokladov.htm).

Выходные данные сборников и метаданные статей и тезисов размещены в следующих информационных системах:

1. Электронный архив материалов Международной объединенной научной конференции «Интернет и современное общество»: http://ojs.ifmo.ru/index.php/IMS.

2. Научная электронная библиотека (с индексацией в Российском индексе научного цитирования, РИНЦ): http://elibrary.ru:

- Информационное общество: образование, наука, культура и технологии будущего: сборник научных статей (http://elibrary.ru/item.asp?id=27548341).

- Государство и граждане в электронной среде: сборник научных статей (http://elibrary.ru/item.asp?id=27478455).

- Компьютерная лингвистика и вычислительные онтологии: сборник научных статей (http://elibrary.ru/item.asp?id=27367632).

- Интернет и современное общество: сборник тезисов (http://elibrary.ru/item.asp?id=27478408).

- EVA 2016 SAINT PETERSBURG. Electronic Imaging \& the Visual Arts (http://elibrary.ru/item.asp?itemid=27478301\&id=27478301).

3. Научное информационное пространство «Соционет»: https://socionet.ru.

4. Самый крупный мировой агрегатор научной информации OCLC WorldCat: http://www.worldcat.org.

Всего в мероприятиях Недели технологий информационного общества участвовало 357 человек, из них - 43 иностранные коллеги.

International Culture \& Technology Studies, Vol. 2, No. 1 


\title{
First Information Society and Technology Week in Saint-Petersburg
}

\author{
M.V. Kudriavtceva ${ }^{1,2}$, D.E. Prokudin ${ }^{2,1}$, A.A. Smolin ${ }^{1,2}$, A.V. Chugunov ${ }^{1}$ \\ ${ }^{1}$ ITMO University, Russia \\ ${ }^{2}$ Saint-Petersburg State University, Russia
}

\begin{abstract}
From 21 to 24 June 2016 In St. Petersburg took place the Information Society and Technology Week, which included a number of scientific events (conferences, round tables and symposia). The basic event of the Week is traditionally held since 1998, the joint scientific conference "Internet and modern society" (IMS). This review reveals major themes and issues that were discussed at the scientific events of the Information Society and Technology Week held in 2016 for the first time.
\end{abstract}

Keywords: information society technology, conference, round table, symposium, Internet, modern society. 